\title{
Perlawanan Hegemoni Budaya dan Mitos pada Karya Seni Rupa Digital Biennale Jatim
}

\section{Counter Hegemony of Cultural and Myths in the East Java Biennale Digital Artwork}

\author{
Jokhanan Kristiyono \\ Program Studi Ilmu Komunikasi, Stikosa-AWS \\ Alamat: Nginden Intan Timur I No. 18, Nginden jangkungan, Kecamatan Sukolilo, \\ Surabaya, Indonesia 60118 \\ Email: jokhanan.k@gmail.com
}

\begin{abstract}
Abstrak
Penelitian ini menganalisis praktik seni melalui karya seni rupa digital yang dilakukan oleh seniman digital yang tergabung pada komunitas seni Biennale Jatim. Karya seni yang dianalisis ini untuk memahami secara mendalam dan eksploratif bagaimana ekspresi perlawanan dominasi dan hegemoni budaya, dominasi mitos yang melembaga pada masyarakat. Dengan pendekatan studi kualitatif melalui metode etnografi digital, peneliti melakukan eksplorasi secara medalam dengan observasi partisipasi proses penciptaan karya dan instalasi karya seni pada pameran Biennale Jatim 7. Dua karya seni yang dianalisis pada penelitian ini menunjukkan sebuah temuan bahwa gambaran nyata tentang perlawanan atas hegemoni (counter hegemony) lewat karya-karya seni. Perlawanan terhadap kondisi sosial masyarakat dan perlawanan terhadap budaya dan mitos pada masyarakat. Para seniman muda yang tergabung di komunitas seni digital Biennale Jawa Timur ini mengganggap praktik seni pada budaya Barat telah melakukan alienisasi terhadap masyarakat di Indonesia terutama masyarakat seni. Sebagai dampaknya, masyarakat Indonesia yang memiliki kultur sosial sangat berbeda dengan Barat, menjadi kaum yang inferior. Implikasi analisis teoritik yang dihasilkan pada penelitian ini yaitu kritik tersendiri untuk teori hegemoni Gramsci yang dikembangkan lagi oleh Cox dan Schilthuis (2012), teori perlawanan hegemoni (counter hegemony) Cox tidak dikupas secara detil untuk kelompok masyarakat yang pada dasarnya terbentuk kritis secara natural seperti kelompok seni modern yaitu komunitas seni Biennale Jawa Timur. Komunitas seni Biennale Jawa Timur ini melakukan proses penciptaan karya bersama masyarakat dengan melakukan praksis seni dan fungsi seni bersama masyarakat lewat penciptaan karya melalui pemberdayaan masyarakat. Komunitas ini melakukannya melalui penciptaan karya seni dan membangun jejaring komunitas (network community).
\end{abstract}

Kata kunci: etnografi digital, praktik seni, karya seni digital, hegemoni budaya, perlawanan hegemoni dan mitos

\begin{abstract}
This study analyzes art practices through digital artworks by digital artists who are members of the East Java Biennale art community. The works of art that are analyzed are to see deeply and exploratively how the expression of resistance to cultural domination and hegemony, the domination of institutionalized myths in society is expressed. With a qualitative study approach through the digital ethnography method, researcher undertook deep exploration by observing the participation of the process of creating works and installing artworks at the East Java Biennale 7. Two works of art analyzed in this study showed a research finding that is a real picture of resistance to hegemony (counter-hegemony) through works of art. Resistance to the social conditions of society and resistance to culture and myths in society. These young artists who are members of the digital art community of the East Java Biennale think that art practices in Western culture have alienation society in Indonesia, especially the art community. As a result, Indonesian people, who have a very different social culture from the West, have become inferior. The implication of the theoretical analysis produced in this study is a separate criticism for Gramsci's hegemony theory which was further developed by Cox and Schilthuis (2012), Cox's counter hegemony theory is not discussed in detail for groups of people who are basically formed naturally critically like groups modern art, East Java Biennale art community. This community carries out the
\end{abstract}


process of creating works with the community by carrying out art praxis and art functions with the community through creating works through community empowerment. This community does this through the creation of works of art and building a network community.

Keywords: digital ethnography, digital artworks; east java biennale; cultural hegemony; counter hegemony

Biokultur, 2020, 9 (2): 76-86. DOI: http://dx.doi.org/10.20473/bk.v9i2.22365.

Article History:

Received September 30, 2020; Accepted November 19, 2020; Published Online November 20, 2020

(c) (i) (2) (2)

\section{Pendahuluan}

Istilah hegemoni budaya dalam filsafat dan sosiologi memiliki denotasi dan konotasi yang berarti aturan dan kepemimpinan. Hegemoni dalam politik adalah metode geopolitik imperial yang melakukan dominasi secara tidak langsung, kelas penguasa (dalam hal ini adalah pemimpin negara atau penguasa politik) mengatur struktur dan serikat di bawahnya dengan intervensi, bukan dengan kekuatan militer (Rakhmat 1997). Perubahan dan perkembangan teknologi komunikasi informasi yang berlangsung cepat telah menimbulkan pergolakan kehidupan sosial secara transisional. Karya seni dan pagelaran seni mengalami ganguan dan ancaman baru terutama dari kelompok komunal seperti agama, etnis dan golongan tertentu termasuk bentuk dominasi dan determinasi budaya mainstream yang terjadi di Indonesia (Ida 2015).

Teknologi digital menimbulkan perluasan dan peningkatan bentuk konektivitas. Namun sisi lain bahkan pada saat yang bersamaan, teknologi digital juga menghasilkan bentuk informasi yang salah. Kesalahan komunikasi atau miskomunikasi. Efek negatif yang ditimbulkan pada kehidupan sosial budaya bisa sangat dramatis dan terkadang fatal. Kesenian dan ekspresi budaya para seniman di Indonesia sebagai masyarakat sosial, juga tidak luput ikut merasakan dampaknya (Kristiyono 2017).

Bentuk hegemoni baru atau digital hegemony ini menjadi perhatian khusus oleh para aktivitas seniman digital Biennale Jawa Timur. Lewat karya-karya format digital pula para seniman ini mengkomunikasikan karya seninya sebagai bentuk perlawanan diam, protes dan mengkritisi hegemoni yang terjadi di masyarakat. Hegemoni atas ideologi, norma, dan mitos (Kristiyono \& Ida 2020).

Kegiatan "protes diam" yang dilakukan komunitas seniman digital Jawa Timur melalui pameran karya seni digital Biennale sudah berlangsung sejak tahun 2003 dan terus secara aktif diselenggarakan setiap dua tahun sekali. Tahun 2017 tepatnya pada tangga 9 - 22 Oktober lalu Biennale Jawa Timur kembali mengadakan pameran karya seni digital Biennale Jawa Timur 7, dengan memamerkan 27 karya seni digital dari karya 24 orang seniman digital di Indonesia. 
Fenomena sosial ini menarik untuk diteliti karena aktivitas digital (digital activism) yang dilakukan oleh para seniman digital ini merupakan gerakan sosial atau gerakan digital dalam bentuk pameran karya seni. Tujuannya untuk menunjukkan kepada masyarakat aksi protes seniman terhadap dominasi realitas dunia, negara dan masyarakat (counter hegemony).

Terdapat beberapa karya seni media digital pada pameran instalasi Biennale Jatim 2017 lalu yang menunjukkan dengan cukup jelas perlawanan dan aksi protes yang dilakukan oleh seniman dan komunitas Biennale ini. Seperti contoh karya seni "Berbicara dengan Ruh" karya Abdul Khafidz Fadli yang menunjukkan aksi protesnya terhadap mitos berbicara dengan ruh melalui ritual-ritual kepercayaan. Atau karya seni digital videografis Kun Fayakun oleh Gelar Soemantri yang memperlihatkan aktifitas hacktivism terhadap karya seni lukis yang divisualgrafiskan menjadi karya seni video digital. Pesan perlawanannya dialamatkan kepada budaya mainstream yang menempatkan karya seni lukis menjadi yang utama dalam budaya seni. Analisis perlawanan dan gerakan aksi protes karya seni tersebut diangkat dalam penelitian ini.

Komunitas seni ini mengkomunikasikan sikap, pikiran, dan kepentingan mereka melalui karya seni format digitalnya. Karya-karya mereka mengirimkan pesan perlawanan, protes, dan kritik terhadap hegemoni yang terbentuk di masyarakat. Penguasaan ideologi atau dominasi ideologi oleh kelompok tertentu yang membuat norma hingga mitos yang dominan terlembaga dalam memori individu maupun kelompok. Perlawanan dilakukan melalui kegiatan seni media digital (digital media arts) yang mereka produksi menggunakan teknologi komunikasi digital adalah bentuk "protes diam" para seniman atas hegemoni itu (Gerbaudo 2014).

Hegemoni budaya merupakan dominasi terhadap masyarakat dengan ragam budaya seperti Indonesia yang masyarakatnya berasal dari berbagai suku dan memiliki berbagai macam ragam budaya. Dominasi dilakukan oleh kelas penguasa dengan membentuk dan atau memanipulasi budaya masyarakat.

Dominasi dan determinasi dari sisi ideologi, persepsi, norma, nilai, mitos, bahkan hingga pada adat istiadat budaya masyarakat. Pandangan kelompok tertentu, dalam hal ini kelas penguasa, yang mendominasi kemudian menjadi norma budaya masyarakat umum tanpa paksaan. Gerakan perlawanan terhadap hegemoni adalah gagasan yang dikembangkan oleh Antonio Gramsci (1995) untuk mendefinisikan cara orang mengembangkan ide dan wacana untuk menantang asumsi dominan, keyakinan dan pola perilaku yang mapan (Cox \& Schilthuis 2012).

Komunitas-komunitas seni digital di Indonesia terus bertumbuh dan bergerak, salah satu contohnya adalah Biennale Jawa Timur. Komunitas ini melakukan aktifitas seni berformat digital dengan menjadi pelopor gerakan-gerakan sosial komunitas seniman digital di Indonesia lainnya. Komunitas ini memproduksi karya seni berbasis teknologi dan kemudian mengkomunikasikan pesannya kepada masyarakat lewat gelaran karya seni para seniman muda Indonesia melalui pameran instalasi karya seni digital Biennale Jawa Timur. Karya- 
karya seni mereka mengirimkan pesan-pesan perlawanan terhadap kondisi sosial masyarakat (Kumar 2011).

Penelitian ini menganalisis gerakan perlawanan hegemoni (counter hegemony) yang dilakukan oleh komunitas seni Biennale Jawa Timur melalui pameran karya seni. Karya seni instalasi digital yang diteliti sebagai obyek penelitian ini adalah "Berbicara dengan Ruh" karya Abdul Khafidz Fadli, seniman dari Sidoarjo Jawa Timur. Karya seni digital yang kedua yaitu karya seni video multi kanal (multichannel video) yang berjudul "Kun Fayakun" karya Gelar Soemantri. Penelitian ini memberikan proposisi dan pengembangan teori analisa counter hegemony Gramsci yang dikembangkan oleh Cox pada tahun 2012 pada konteks analisis hegemoni budaya. Selain itu juga menunjukkan bahwa melalui karya seni digital, praktik-praktik perlawanan hegemoni (counter hegemony) dilakukan secara masif dan tegas bagaimana perlawanan terhadap hegemoni budaya, mitos dan norma pada masyarakat ditunjukkan melalui karya seni digital (Lim 2014).

\section{Metode}

Penelitian ini menggunakan metode digital etnografi. Peneliti melakukan observasi partisipatif dalam proses produksi karya seni digital pada karya seni digital seniman digital Biennale di Jatim. Peneliti menganalisis dan mendeskripsikan bagaimana perilaku perlawanan dan aktivistas yang dilakukan melalui penciptaan karya seni digital sebagai perlawanan kemapanan-kemapanan ideologis, mitos-mitos, dan ide-ide mainstream yang seolah taken for granted atau ada begitu saja di masyarakat dan dipercaya sebagai sebuah kebenaran dan pengetahuan yang ada (Kristiyono \& Ida 2019).

Studi dengan pendekatan etnografi bertujuan untuk menghasilkan kemajemukan dan kompleksitas terhadap budaya, termasuk asumsi tidak terkatakan atau realitas yang diterima begitu saja, atau dapat disebut Thick Description (Geertz 2008). Digital Etnografi merupakan perkembangan dari studi Etnografi yang berakar dan berawal dari studi Antropologi dengan metodologi kualitatif. Sangat tepat dan cocok untuk mempelajari keyakinan, interaksi sosial, dan perilaku kelompok masyarakat seperti komunitas seni digital Biennale Jawa Timur. Melibatkan partisipasi dan observasi selama periode waktu tertentu, dan interpretasi dari pengumpulan data (Denzin \& Lincoln 2011).

Kegiatan realitas sosial kelompok seniman digital Indonesia, ditentukan unit analisisnya, yaitu tiga unit analisis (situasi, kegiatan dan tindakan). Unit analisis ini untuk dapat menggambarkan dan mendeskripsikan digital activism sebagai gerakan sosial dan proses produksi media komunikasi (karya seni digital) sebagai bentuk protes atau kritik terhadap realitas sosial, yaitu ideologi, norma, dan mitos yang berkembang di masyarakat. Dengan menggunakan teori Hegemoni Gramsci, peneliti menganalisis ketiga unit analisis untuk dapat mendeskripsikan bentuk counter hegemony oleh seniman digital Indonesia dalam karya seni digital yang diciptakannya sampai pada tahap dikomunikasikan dalam bentuk kegiatan pameran seni digital. Penelitian ini menggunakan metode etnografi digital (Pink et al. 2016). 


\section{Hasil dan Pembahasan}

\section{Kritik Hegemoni Budaya dalam Karya Seni Instalasi "Berbicara dengan Ruh" karya Abdul Khafidz Fadli}

Seni rupa modern yang terjadi di Indonesia menunjukkan perkembangan ke dua arah yang berlawanan. Seni rupa modern secara total dan sengaja tidak berbasis pada tradisi atau budaya. Seni rupa modern ini melalui proses eksogen, yaitu tercipta karena adanya hegemoni dan dominasi dari luar. Seni rupa modern di Indonesia yang bersifat eksogen ini tercipta karena adanya dominasi dari seni rupa Barat. Seni rupa modern lainnya, menjadikan tradisi budaya sebagai referensi penciptaan karya seni rupa modern. Seni rupa modern ini melalui proses endogen. Karya cipta seni rupa yang melalui proses dan berasal dari dalam (internal) seperti tradisi dan budaya lokal (Djatiprambudi 2017).

Karya seni rupa instalasi ruang yang dianalisa pada penelitian ini berjudul "Berbicara dengan Ruh" karya Abdul Khafidz Fadli, seniman dari Sidoarjo Jawa Timur. Karya cipta seni rupa yang melalui proses endogen, yaitu karya seni yang diciptakan dan berasal dari tradisi dan budaya lokal. Karya instalasi ruang berukuran 3x3 meter yang dipamerkan pada pameran Biennale Jatim 7 lalu ini menunjukkan proses ritual budaya berbicara dengan ruh. Budaya yang hingga saat ini masih dipercayai dan dilakukan oleh beberapa kelompok masyarakat.

Seniman yang biasa disapa Toyol a.k.a. Toyol Dolanan Nuklir ini adalah "engineer embongan", dengan latar belakang pendidikan Mechanical Engineering ini gemar bereksperimen menghasilkan "barang" unik. Barang unik sebagai karya seni dengan peralatan elektronik yang digabungkan dengan barang tradisional dari budaya lokal. Barangbarang yang tidak terpakai dan rongsokan ini di tangan kreatif Toyol menjadi sebuah karya seni instalasi yang sangat menarik. Imajinasi liar dengan mentransformasi dan menggabungkan barang-barang tersebut menjadi sebuah karya seni. Karya seni yang menimbulkan suara "teriakan-teriakan", yang menunjukkan orasi kejamnya dunia. Pada Biennale Jatim 7 ini, Toyol bereksperimen dengan menciptakan karya seni yang berasal dari peralatan elektronika dan benda-benda tradisional seperti kurung ayam, tampah rotan, dan barang-barang sesajen. Barang-barang sesejen ini dipercaya merupakan tradisi budaya ritual kepercayaan. Sebuah kepercayaan yang melakukan hegemoni budaya, menjadi tradisi yang juga melembaga pada masyarakat dalam struktur sosial. 


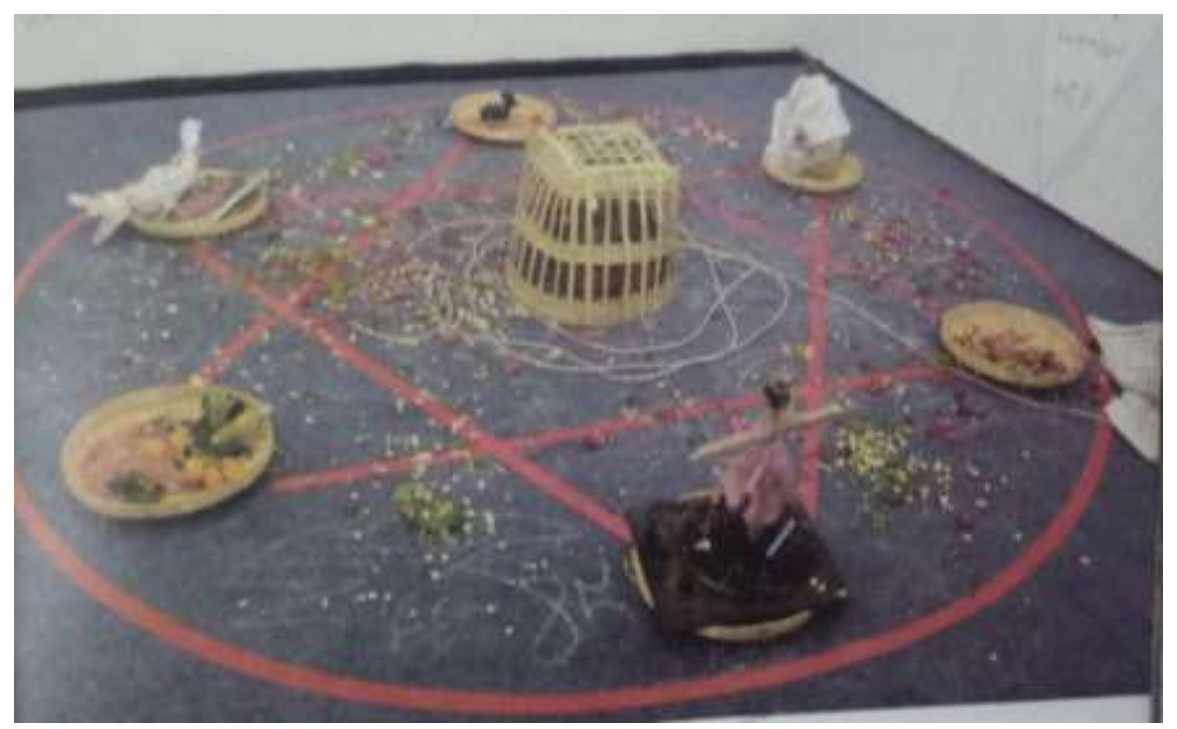

Gambar 1. Karya seni instalasi Ruang "Berbicara Dengan Ruh" karya Toyol Dolanan Nuklir Sumber: Katalog Biennale Jatim \#7

Karya seni instalasi ruangan 3x3 meter dengan aneka perangkat elektronika, sensor gerak, suara, rajah "jimat" dan sesajen ini diberi judul "Berbicara Dengan Ruh" merupakan tanggapan Toyol terhadap praktik perdukunan. Praktik ritual kepercayaan yang masih mendominasi dan melembaga pada masyarakat modern saat ini.

Berbicara dengan ruh merupakan kegiatan ritual atau praktik yang kerap dilakukan oleh "orang pintar" atau biasa disebut dukun. Praktik yang dilakukan untuk menyembuhkan orang sakit karena hal gaib, atau bahkan praktik kepercayaan yang dilakukan untuk menciptakan ketakutan dan kengerian dalam masyarakat.

Tujuan dari karya seni instalasi ruang ini adalah menunjukkan kepada masyarakat bahwa masih ada hegemoni budaya ritual kepercayaan dalam masyarkat. Melalui karya visual, praktik ritual berdialog dengan ruh ditunjukkan dengan sensor gerak yang secara otomatis menimbulkan suara-suara kengerian dan ketakutan. Karya seni instalasi ruang ini seca menunjukkan sebuah bentuk perlawanan terhadap mitos dan nilai dalam masyarakat. Karya seni instalasi ruang dengan sentuhan digital elektronika sensor geraan dan suara (digital audio) merupakan bentuk karya seni baru yang menunjukkan mitos-mitos dalam budaya Indonesia. Digambarkan sesajen dan jimat sebagai visualisasi praktik perdukunan yang masih marak terjadi pada masyarakat modern di Indonesia.

Mitos "berbicara dengan ruh" melalui praktik perdukunan yang masih tumbuh pada masyarakat Indonesia yang sudah menjadi masyarakat informasi (M Castells, 2010). Budaya yang memuja dan berinteraksi dengan ruh leluhur melalui praktik perdukuna masih dipercaya oleh masyarakat agar selalu mendapatkan rejeki dan kekayaan. Pesannya adalah sebuah kritik terhadap nilai sosial dalam bentuk mitos yang muncul dalam budaya. Sebuah karya seni bermuatan pesan perlawanan atas hegemoni nilai sosial dan mitos masyarakat. 


\section{Perlawanan Hegemoni Budaya dan Mitos pada Karya Gelar Sumantri "KUN FAYAKUN"}

Gelar Sumantri, seniman aktif sejak tahun 2006 yang memulai keikutsertaannya dalam pameran fotografi "Jeda-Forum Lenteng Photography" di Yogyakarta. Seniman ini lebih berfokus pada seni video dengan proses kreatif pengerjaannya secara berkeliling, mulai dari Papua hingga Seoul, Korea Selatan. Karya seni video ciptaannya sangat beragam, mulai dari video instalasi, video music hingga video pertunjukan (performance video).

Karya seninya yang dianalisis pada penelitian ini adalah karya seni video multi kanal (multichannel video) yang berjudul "Kun Fayakun". Karya seni video ini menggambarkan kenangan atau memori masa kecilnya, seperti melakukan menghitamkan gigi atau menambahkan kumis pada foto-foto orang terkenal yang ada di Kalendar. "Keusilan" masa kanak-kanaknya ini dilakukannya kembali atau dipraktikkan ulang dengan menggunakan aplikasi smartphone dengan menambahkan aset animasi ke dalam foto.

Foto yang digunakan oleh Gelar Soemantri adalah gambar digital yang ada di Internet dan sebagian adalah gambar lukisan koleksi Galeri Nasional dan koleksi Istana Negara. Tujuan dari karya seni video ini adalah mempertanyakan kembali esensi sebuah karya seni ketika karya seni (foto lukisan) tersebut berada di Internet dan bisa diakses oleh publik.

Karya seni tersebut menjadi milik siapa? Sejauh apa batas "Kesakralan" karya-karya lukisan yang dikoleksi oleh Lembaga atau Institusi Negara dalam hal ini Galeri Nasional Indonesia dan Istana Negara. "Kesakralan" itu dinilai Gelar Sumantri telah membangun jarak antara penikmat seni (publik) dengan karya seni itu sendiri.

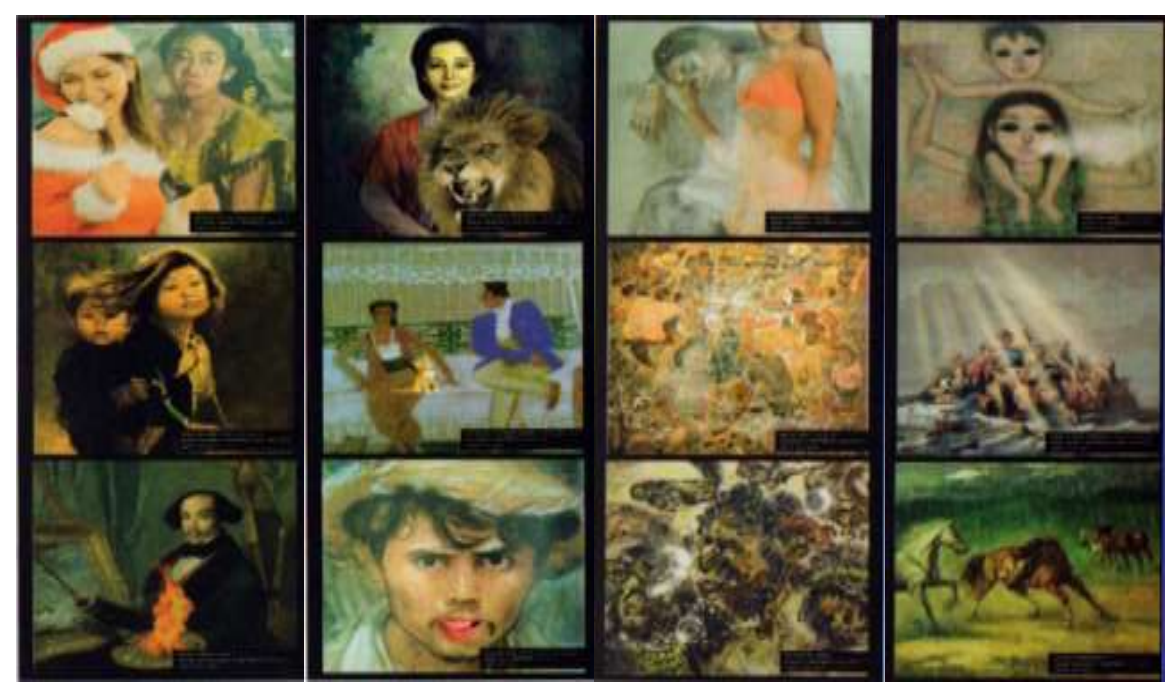

Gambar 2. Video Digital Imaging “Kun Fayakun” karya Gelar Soemantri Sumber: Katalog Biennale Jatim \#7 
Bentuk protes diam yang dilakukan oleh seniman ini adalah melakukan hacktivism terhadap karya seni lukisan koleksi Galeri Nasional dan Istana Negara dalam bentuk videografis. Apresiasi dalam bentuk pembuatan imajinasi baru dengan menambahkan aset animasi pada foto lukisan tersebut (Jurriëns 2017). Gelar Soemantri sebagai seniman yang melakukan hacktivism karya seni lukisan dan menghasilkan karya seni yang baru membubuhkan tanda personal yaitu SMTGRL X beserta nama pelukis asli dari lukisan-lukisan yang di rubah bentuk olehnya. Tindakan ini sebagai bentuk tanggungjawab kepada penikmat karya seninya bahwa karya seni video ini dibuat oleh seniman yang berbeda dan sudah berubah bentuk dalam bentuk format digital imaging animasi.

Karya seni Gelar Sumantri menunjukkan perlawanan atas hegemoni (counter hegemony) berupa dominasi karya seni mainstream seni lukis di Indonesia. Ia melakukan proses reproduksi hacktivism dengan mendekontruksi karya seni lukis yang dianggapnya sebagai bentuk dominasi seni rupa, lalu mentransformasikan media lukis menjadi media digital. Lukisan yang lama diubah bentuk menjadi visual grafis animasi yang menceritakan tentang mitos-mitos yang dipercayai dan diyakini oleh masyarakat Indonesia.

Seni lukis merupakan salah satu penampakan seni mainstream di masyarakat. Seni yang menjadi acuan utama dalam perkembangan seni di Barat dan melakukan determinasi di Asia (termasuk di Indonesia). Contohnya adalah seni lukis karya maestro Basuki Abdullah yang kemudian menjelma menjadi karya seni yang sakral dan sekaligus menjadi karya seni yang borjuis, karena hanya bisa dimiliki dan dinikmati oleh golongan tertentu.

Menurut Gramsci, semua individu adalah filosofis dan berpikiran bebas. Kapasitas pemikiran filosofis ini memungkinkan orang, terutama kelas pekerja termasuk pelaku seni (seniman), untuk memahami cara-cara hegemoni budaya mereproduksi posisi ekonomi dan sosial mereka yang dominan. Kesadaran ini adalah inspirasi kritis untuk tindakan untuk menantang hegemoni budaya (Cox \& Schilthuis 2012).

Apa yang dilakukan Gelar Sumantri adalah bentuk pendobrakan dan perlawanan terhadap hegemoni karya seni lukis (mainstream art). Ia melakukannya dengan tindakan hacktivism atas karya seni. Tampak sekali seniman ini tetap ingin memberikan apresiasi atas kaya aslinya dengan "hanya" menambahkan aset animasi pada foto lukisan aslinya. Bagamana pun dengan tindakannya itu ia sudah berhasil membangun imajinasi baru pada wilayah kesadaran penikmat karyanya.

Selain perlawanan terhadap hegemoni seni lukis, karya seni ini secara metadata discourse menunjukkan sebuah bentuk perlawanan terhadap mitos dan nilai dalam masyarakat. Salah satu contoh karya seni animasi besutan seniman ini adalah lukisan "Ratu Pantai Selatan" karya Basuki Abdullah. Lewat sentuhan nakal digital imaging, lukisan ini menjadi bentuk karya seni baru yang menunjukkan mitos-mitos dalam budaya Indonesia. Digambarkan gerakan Ratu Pantai Selatan yang mengeluarkan lembaran-lembaran uang dalam bentuk mata uang asing (Dolar). 
Mitos "pesugihan" yang terus tumbuh pada masyarakat Indonesia. Budaya yang memuja Ratu Pantai Selatan agar selalu mendapatkan rejeki dan kekayaan. Pesannya adalah sebuah kritik terhadap nilai sosial dalam bentuk mitos yang muncul dalam budaya. Sebuah karya seni bermuatan pesan perlawanan atas hegemoni nilai sosial dan mitos masyarakat (Ida 2015).

\section{Simpulan}

Karya seni digital yang dianalisis pada penelitian ini menunjukkan sebuah perlawanan dominasi dan hegemoni budaya yang terjadi di masyarakat. Cox \& Schilthuis pada bukunya yang berjudul Hegemony and Counter Hegemony (2012) menjelaskan pendapat Gramsci tentang hegemoni kebudayaan bagaimana kelas dominan, khususnya borjuis, mendominasi wacana dan simbol budaya. Melalui manipulasi simbol dan nilai, kaum borjuis mempertahankan kontrol psikologis pada masyarakat sehingga membuat posisinya dominan dalam masyarakat. Perlawanan terhadap hegemoni adalah filosofis praktis untuk menantang posisi hegemonik dari budaya borjuis.

Seniman pada dasarnya merupakan individu yang menempatkan dirinya berada di luar struktur sosial. Aktivitas seninya tampil dalam bentuk karya seni dan pagelaran seni. Menariknya, struktur sosial seperti struktur ekonomi, struktur politik dan hingga struktur budaya tampaknya juga telah ikut melakukan dominasi dan determinasi pada aktivitas seni. Kelompok-kelompok komunal dalam struktur agama, struktur etnis dan budaya, hingga struktur golongan tertentu ikut melakukan determinasi dalam penentuan karya seni termasuk pagelaran seni.

Determinasi itu membuat seniman mengalami kesulitan melakukan aktivitas seninya. Kesulitan beraktvitas seni itu kian terasa ketika seniman dan komunitas seni melakukan praktik seni sebagai bentuk perlawanan dengan tujuan mendekontruksi struktur sosial yang terjadi di masyarakat. Struktur sosial melakukan dominasi terhadap perkembangan seni (Mouffe 2014).

Implikasi analisis teoritik yang dihasilkan pada penelitian ini yaitu kritik tersendiri untuk teori hegemoni Gramsci yang dikembangkan lagi oleh Cox dan Schilthuis (2012), teori perlawanan hegemoni (counter hegemony) Cox tidak dikupas secara detil untuk kelompok masyarakat yang pada dasarnya terbentuk kritis secara natural seperti kelompok seni modern yaitu komunitas seni Biennale Jawa Timur. Komunitas seni Biennale Jawa Timur ini melakukan proses penciptaan karya bersama masyarakat dengan melakukan praksis seni dan fungsi seni bersama masyarakat lewat penciptaan karya melalui pemberdayaan masyarakat. Komunitas ini melakukannya melalui penciptaan karya seni dan membangun jejaring komunitas (network community).

Analisis pengembangan teori counter-hegemony yang berbasis teori dasar Gramsci dapat dilakukan pada topik-topik penelitian lain merujuk realitas kehidupan masyarakat modern saat ini. Gerakan sosial atau social movements yang terjadi di masyarakat informasi di era digital ini kerap terjadi, fenomena realitas sosial yang menarik dikaji menggunakan Analisis 
teoritis kritis perlawanan sosial (counter-hegemony). Bagaimana masyarakat informasi yang terus berjejaring dan berkembang secara sosial melalui dukungan teknologi informasi dapat merubah media dan budaya (Castells 2010). Kajian media dan budaya dapat menjadi dasar pemikiran kritis dalam menganalisis realitas tersebut khususnya gerakan perlawanan terhadap ideologi politik yang saat ini berkembang di masyarakat informasi di Indonesia (Gramsci 2006).

\section{Daftar Pustaka}

Castells M (2010) The Rise of the Network Society. Massachusetts: Blackwell Publishing. https://doi.org/10.2307/1252090.

Cox RH \& Schilthuis A (2012) Hegemony and counterhegemony. The Wiley-Blackwell Encyclopedia of Globalization.

Denzin NK \& Lincoln YS (2011) The SAGE handbook of qualitative research. Sage.

Djatiprambudi D (2017) Penciptaan Seni Sebagai Penelitian. In Seminar Nasional Seni dan Desain 2017: 24-30. State University of Surabaya.

Geertz C (2008) Thick description: Toward an interpretive theory of culture. In The Cultural Geography Reader: 41-51. Routledge.

Gerbaudo P (2014) The persistence of collectivity in digital protest. Information, Communication \& Society, 17 (2): 264-268.

Gramsci A (2006) HEGEMONY, INTELLECTUALS. Cultural Theory and Popular Culture: A Reader, 1, 85.

Ida R (2015) Imagining Community in Contemporary Surabaya. Performing Contemporary Indonesia: Celebrating Identity, Constructing Community, 83.

Jurriëns E (2017). Visual Media in Indonesia: Video Vanguard. Routledge.

Kristiyono J (2017) Budaya Internet: Perkembangan Teknologi Informasi dan Komunikasi dalam Mendukung Penggunaan Media di Masyarakat. Scriptura: 23-30. https://doi.org/10.9744/scriptura.5.1.23-30.

Kristiyono J \& Ida R (2019) Digital Etnometodologi: Studi Media dan Budaya pada Masyarakat Informasi di Era Digital. ETTISAL: Journal of Communication, 4 (2): 109-120. 
Kristiyono J \& Ida R (2020) Counter-hegemony of the East Java Biennale art community against the domination of hoax content reproduction. Masyarakat, Kebudayaan Dan Politik, 33 (1): 26-35.

Kumar S (2011) The exercise of hegemony in contemporary culture and media, and the need for a counter-hegemony initiative. Social Scientist, 39 (11/12): 33.

Lim M (2014) Seeing spatially: people, networks and movements in digital and urban spaces. International Development Planning Review, 36 (1): 51-72.

Mouffe C (2014) Hegemony and ideology in Gramsci. In Gramsci and Marxist Theory (RLE: Gramsci): 178-214. Routledge.

Pink S, Horst H, John P, Hjorth L, Lewis T, \& Tacchi J (2016) Digital Ethnography: Principles and Practice. SAGE. https://doi.org/10.1017/CBO9781107415324.004.

Rakhmat J (1997) Hegemoni budaya. Yogyakarta: Yayasan Bentang Budaya. 